\title{
Clinical Presentation and Biochemical Abnormalities in Patients Presented with Diabetic Ketoacidosis in BIRDEM Hospital
}

Suraiya Nazneen ${ }^{*}$, Fatema Ahmed ${ }^{2 *}$, SM Ashrafuzzaman ${ }^{3}$, Khwaja Nazim Uddin 4 , ASM Areef Ahsan ${ }^{5}$, Mohammad Omar Faruq ${ }^{6}$, Kaniz Fatema ${ }^{7}$, Debashish Kumar Saha ${ }^{8}$, Madhurima Saha ${ }^{9}$, Kamrul Hasan Sohel $^{10}$

\begin{abstract}
Objective: To see the clinical presentation and biochemical abnormalities in hospitalized patients of Diabetic ketoacidosis.

Methodology: This cross sectional observational study was carried enrolling 55 subjects with Diabetic ketoacidosis, in the Department of Medicine, BIRDEM General Hospital, Dhaka, over a period of six months starting from April 2013 to September 2013.

Results: The mean age was $48.35 \pm 16.76$ with age range from 30 to 68 years. Infection (pneumonia, urinary tract infection, cellulitis) 22(40\%), omission of insulin or drugs 14 (25.4\%), myocardial infarction 5(9.0\%), and reduction of insulin dose 3(5.4\%) worked as precipitating cause.Most patients had drowsiness $16(29.0 \%)$, moderate dehydration $30(55.5 \%)$, signs of infection 22(40\%). About 13(23.56\%) had Kussmaul's type of respiratory pattern. Other signs were less obvious. Majority of the subjects 40(72.7\%) had 3+ ketonuria at the time of admission in hospital. About $32(58.1 \%)$ of the known diabetic patients were on insulin from the beginning of their diagnosis.19 (34.4\%) were initially on OHA followed by insulin and $14(25.4 \%)$ patients took OHA alone. 7 patients were on dietary modification and exercise without any drugs. Majority 52 (96.46\%) patients had blood sugar level between 21-34 mmol/l and mean HbAlc was 12.31(SD \pm 2.50$)$.About 4(7.2\%) patients had severe hyponatraemia and 22(40\%) patients had hypokalaemia. Eight (14.5\%) patients had severe acidosis while 18(32.7\%) patients had only mild acidosis. Most of the subjects 29(52.7\%) had moderate acidosis.

Complete cure from DKA was observed in 53(96.3\%) subjects. Only 2(3.6\%) subjects developed cerebral oedema. It took 4 to 5 days in mild group, 6 to 8 days in moderate DKA and more than 9 days in severe DKA for recovery.
\end{abstract}

Conclusion: From the study result it could be concluded that infection control and regular administration of insulin or control of diabetes and proper Diabetes Self Management Education (DSME) can prevent diabetic ketoacidosis.

Key words: Diabetic ketoacidosis, clinical presentation, precipitating cause, clinical presentation, biochemical abnormalities.

\section{Introduction:}

Diabetic ketoacidosis (DKA) is a medical emergency. ${ }^{1}$ It may be the presenting feature of type 1 diabetes but more frequently it occurs in established diabetes patients- both type 1 and type 2 . Infection is the commonest precipitating cause. ${ }^{2}$ Dosing errors or discontinuation of insulin therapy is also important. Type 1 diabetic patients in poor populations with limited access to health care facilities may develop ketoacidosis because they run out of insulin, which can happen in affluent countries like USA as well. ${ }^{3}$ Recent reports from the USA and Asia highlighted cases that occur apparently spontaneously in patients with classical type 2 syndrome, who can be treated without insulin after the episode has resolved. ${ }^{4}$ Patients of type 2 diabetes may develop ketoacidosis under severe stress such as sepsis, trauma, or major surgery. Management of DKA consists of rehydration with intravenous fluid, administration of insulin and replacement of electrolytes.

The cardinal biochemical features ${ }^{5}$ of diabetic ketoacidosis are hyperglycaemia, hyperketonaemia and metabolic acidosis. The diagnostic criteria used here include a plasma bicarbonate concentration of $15 \mathrm{~m}$.mol per litre or less with significant ketosis (urine ketostix reaction atleast ++ or plasma ketostix reaction + or more) ${ }^{6}$

The hyperglycaemia causes a profound osmotic diuresis leading to dehydration and electrolyte loss, particularly of sodium and potassium. Potassium loss is exacerbated by secondary hyperaldosteronism as a result of reduced renal perfusion. Ketosis results from insulin deficiency, exacerbated by catecholamines and other stress hormones, resulting in unrestrained lipolysis and supply of FFAs for hepatic ketogenesis. When this exceeds the capacity to metabolise acidic ketones, these accumulate in blood. The resulting metabolic acidosis forces hydrogen ions into cells, displacing potassium ions. ${ }^{7}$

\section{Materials and Methods:}

This cross sectional observational study was carried out over a period of six months starting from April 2013 to September 2013 to evaluate 55 subjects aged 30-68 years diagnosed as diabetic ketoacidosis (DKA) in the Department of Internal Medicine and Endocrinology, Bangladesh Institute of Research and Rehabilitation in Diabetes, Endocrine and Metabolic Disorders (BIRDEM) General Hospital, Shahbagh, 
Dhaka with the aim to see the clinical presentation and biochemical abnormalities in hospitalized patients of DKA. Subjects who presented with features of DKA (whether newly diagnosed or old cases of DM) were enrolled in this study. Patients who had metabolic acidosis due to coexisting conditions like chronic renal failure and DKA were excluded. The objective of the study was discussed in details with the patients or their attendants before their decision to enroll themselves into the study. Clinical examination and laboratory tests were done and data collected. Prior to the commencement of this study permission was obtained from ethical review board of BIRDEM academy. Informed written consent was taken from each patient. Data were collected in a pre-designed structured data collection sheet. Data entry and analysis were done using SPSS for windows version 19.0.

\section{Results:}

The mean age was $48.35 \pm 16.76$ with an age range from 30 to 68 years. Majority of $(38.1 \%)$ the respondents were found in the age group of 40-49. In the study group, male were 32 $(58.1 \%)$ and $23(41.8 \%)$ were female. Half of the patients'

1. Dr. Suraiya Nazneen, FCPS (Medicine), Registrar, Dept. of Critical Care Medicine, BIRDEM General Hospital, Dhaka

2. Dr. Fatema Ahmed, FCPS (Medicine), MD (CCM), Assistant Professor, Dept. of Critical Care Medicine, BIRDEM General Hospital, Dhaka

3. Prof. SM Ashrafuzzaman, DEM, MD (Endocrinology and Metabolism), Professor, Dept. of Endocrinology, BIRDEM General Hospital, Dhaka

4. Prof. Khwaja Nazim Uddin, FCPS (Medicine), FACP, FRCP, Professor of Medicine, BIRDEM General Hospital, Dhaka

5. Prof. ASM Areef Ahsan, FCPS (Medicine), MD (Chest), MD (CCM), Professor and Head, Dept. of Critical Care Medicine, BIRDEM General Hospital, Dhaka

6. Prof. Mohammad Omar Faruq, MD, FACP, FACEP, FCPS, FCCM, Professor, Dept. of Critical Care Medicine, Ibn Sina Hospital, Dhanmondi, Dhaka

7. Dr. Kaniz Fatema, FCPS (Medicine), MD (CCM), Assistant Professor, Dept. of Critical Care Medicine, BIRDEM General Hospital, Dhaka

8. Dr. Debasish Kumar Saha, FCPS (Medicine), Registrar, Dept. of Critical Care Medicine, BIRDEM General Hospital, Dhaka

9. Dr. Madhurima Saha, FCPS (Medicine), Registrar, Dept. of Critical Care Medicine, BIRDEM General Hospital, Dhaka

10. Dr. Kamrul Hasan Sohel, FCPS (Ophthalmology), Consultant, Bangladesh Eye Hospital, Dhaka

*First two authors had equal contributions and should be regarded as Principal author

\section{Corresponding Author :}

Dr. Suraiya Nazneen

Registrar

Department of Critical Care Medicine BIRDEM General Hospital, Dhaka 1000.

E-mail : drnazneen28@gmail.com
BMI was within normal range $(50.9 \%)$ while $20 \%$ were overweight, $16.3 \%$ of the patients found to be underweight.

Table I: Distribution of cases according to precipitating causes

\begin{tabular}{lcc}
\hline Precipitating cause & Number (n) & Percentage (\%) \\
\hline Infection & 22 & 40.0 \\
Omission of insulin/drug & 14 & 25.4 \\
MI & 5 & 09.0 \\
Reduction of insulin & 3 & 05.4 \\
Stroke & 2 & 03.6 \\
Pancreatitis & 2 & 03.6 \\
Surgery & 1 & 01.8 \\
Unidentified & 7 & 12.7 \\
\hline
\end{tabular}

$22(40 \%)$ cases had infections like pneumonia, urinary tract infection, cellulitis etc.

Table II: Presenting features of the study subjects

Presenting features Number (n) Percentage (\%)

Presence of unconsciousness

$\begin{array}{lll}\text { Drowsiness } & 16 & 29.0 \\ \text { Confusion } & 10 & 18.1 \\ \text { Coma } & 02 & 03.6\end{array}$

\section{Dehydration Status}

$\begin{array}{lll}\text { Mild } & 15 & 27.2 \\ \text { Moderate } & 30 & 55.5 \\ \text { Severe } & 10 & 17.1\end{array}$

\section{Respiratory pattern}

Hurried

36

65.4

Kussmaul's

13

Presence of signs of infection

22

40.0

Majority of the subjects $(72.7 \%)$ had $3+$ ketonuria at the time of admission in hospital. (50.9\%) had an HbAlc over 13. (20\%) had HbA1c within 9-10.

Table III: RBS levels at presentation

\begin{tabular}{lcc}
\hline RBS in $\mathrm{mmol} / 1$ & Number $(\mathrm{n})$ & Percentage $(\%)$ \\
\hline$\leq 20$ & 01 & 01.1 \\
$21-34$ & 52 & 96.4 \\
$>35$ & 02 & 02.3 \\
\hline
\end{tabular}


Table IV: Degree of acidosis of the subject

\begin{tabular}{lccc}
\hline $\mathrm{pH}$ & Severity & Number (n) & Percentage (\%) \\
\hline$<7$ & Severe & 08 & 14.5 \\
$7.00-7.24$ & Moderate & 29 & 52.7 \\
$7.25-7.30$ & Mild & 18 & 32.7 \\
Total & & 55 & 100.0 \\
\hline
\end{tabular}

Table V: Electrolyte disturbances at presentation

\begin{tabular}{|c|c|c|}
\hline Electrolyte & Number (n) & Percentage $(\%)$ \\
\hline \multicolumn{3}{|l|}{$\mathbf{N a}$} \\
\hline$<120$ & 04 & 07.2 \\
\hline $121-135$ & 21 & 38.1 \\
\hline $136-145$ & 26 & 47.2 \\
\hline$>146$ & 04 & 07.2 \\
\hline \multicolumn{3}{|l|}{$\mathbf{K}$} \\
\hline$<3.5$ & 22 & 40.0 \\
\hline $3.6-5.2$ & 26 & 47.2 \\
\hline$>5.2$ & 07 & 12.7 \\
\hline \multicolumn{3}{|l|}{ Cl } \\
\hline$<90$ & 06 & 14.5 \\
\hline $90-100$ & 14 & 25.5 \\
\hline$>100$ & 35 & 59.9 \\
\hline \multicolumn{3}{|l|}{$\mathrm{HCO}_{3}$} \\
\hline$<10$ & 8 & 14.5 \\
\hline $10-15$ & 34 & 61.8 \\
\hline
\end{tabular}

During treatment, $7 \quad(12.7 \%)$ subjects developed hypoglycaemia and $22(40 \%)$ subjects developed hypokalaemia. It took 4 to 5 days in mild group, 6 to 8 days in moderate DKA and more than 9 days in severe DKA for recovery.

\section{Discussion:}

DKA is a medical emergency and without treatment it can lead to death. Majority of (38.1\%) the respondents were found in the age group of 40-49. In the study group, male were 32 $(58.1 \%)$ and $23(41.8 \%)$ were female. But female male ratio in a study in Denmark ${ }^{18}$ was 7.2: 5.7. In a recent study in Taipei ${ }^{19}$, it was found that $67 \%$ DKA patients are female. In a small series in India ${ }^{20}$ male: female ratio was $2: 1$. It is not clear why females suffer more from DKA.

It was noted that mean $\mathrm{HbA1c}$ was $12.31(\mathrm{SD} \pm 2.5) \%$ while
Majority [52 (96.46\%)] patients had blood sugar level between 21-34 mmol/1. It was found that half of the patients' BMI was within normal range (50.9\%) while $20 \%$ were overweight; $16.3 \%$ of the patients found to be underweight. In previous study which was conducted by Zabeen $\mathrm{B}$ et $\mathrm{al}^{3}$ it was seen that mean random blood glucose (RBG) and HbAlc were $27.6 \mathrm{mmol} / \mathrm{L}$ and $13.4 \%$ respectively. Rajasoorya et al. ${ }^{4}$ found that blood sugar levels at admission ranged between $351 \mathrm{mg} / \mathrm{dl}$ and $1200 \mathrm{mg} / \mathrm{dl}(\mathrm{mean}=633 \mathrm{mg} / \mathrm{dl})$. The mean serum potassium at diagnosis was $5.1 \mathrm{mmol} / \mathrm{l}$ and the mean calculated serum osmolality was $320 \mathrm{mOsm} / \mathrm{kg}$.

Of the 55 diagnosed DKA patients, infection, missing regular insulin or drugs, MI, stroke, pancreatitis and surgery were precipitating causes. Zabeen $\mathrm{B}$ et $\mathrm{al}^{3}$ observed the same result where it was seen that $28 \%$ had missed insulin and $48 \%$ had overt infection. In another study ${ }^{5}$ it was noted that major precipitating factors for DKA included discontinuation of insulin, infection, and other medical illness in 501 (59.1\%), $136(16.1 \%)$, and $30(3.5 \%)$ of the admissions, respectively. Non-compliance was the most common cause in Korea ${ }^{22}$ whereas in another study in Pakistan ${ }^{23}$ infection precipitated DKA in $63 \%$ cases of type 2 diabetes mellitus.

Most patients had drowsiness (29.0\%), moderate dehydration $(55.5) \%$, signs of infection (40\%). About $23.5 \%$ had Kussmaul's type of respiratory pattern. Others signs were less obvious. In a comparable study ${ }^{4}$ it was noted that presenting symptoms were polyuria and polydipsia $(58 \%)$, nausea and vomiting (52\%), change in sensorium (24\%), hyperventilation $(24 \%)$ and abdominal pain $(18 \%)$. The main clinical findings at admission were dehydration (97\%) acidotic respiration (67\%), coma and confusion (61\%), a clinically detectable source of sepsis (49\%), fever (33\%) and hypotension $(9 \%)$.

Majority of the subjects $(72.7 \%)$ had 3+ ketonuria at the time of admission in hospital. In the Pakistani study similar observation was reported. ${ }^{23}$ Almost all patients had neutrophilic leukocytosis. $15(30 \%)$ patients had WBC count between 11000 and 15000 . In another study ${ }^{8}>65 \%$ patients had leucocytosis and in 55\% patient there was no infection. $26(49.1 \%)$ patients had blood sugar level between $31-35 \mathrm{mmol} / \mathrm{l}$, and fifteen patients $(27.2 \%)$ had blood sugar level between $26-30 \mathrm{mmol} / \mathrm{l}$ while $1.1 \%$ had blood sugar below $20 \mathrm{mmoll} / 1$. Majority of the patients $(50.9 \%)$ had an HbA1c over 13. Almost half of the patients had normal $\mathrm{Na}$ and $\mathrm{K}$ levels at presentation. 7.2\% patients had severe hyponatraemia and $14.5 \%$ had hypokalaemia. $8(14.5 \%)$ of the patients had severe acidosis while $52.7 \%$ patients had only mild acidosis.

Complete cure was observed in $53(96.3 \%)$ subjects. Only 2 (3.6\%) subjects developed cerebral oedema. It took 4 to 5 days in mild group, 6 to 8 days in moderate DKA and more than 9 days in severe DKA for recovery. Previous study ${ }^{3}$ revealed that cerebral edema was seen in $7.5 \%$ subjects. The outcome of treatment in the whole group was good, 46 $(86.7 \%)$ patients recovered without complications, but 7 (13.4\%) patients died. Rajasoorya et al. ${ }^{4}$ in their study 
Bangladesh Crit Care J March 2017; 5 (1): 7-10

revealed that four patients died during the 33 hospitalisations, giving a mortality rate of $10 \%$. Death occurred despite glucose control and stabilization of the ketoacidotic state and was due to uncontrolled septicaemia. In our study due to meticulous management of DKA no death occurred.

\section{Conclusion:}

Bangladesh is a developing country which cannot bear the huge cost related to the complications of diabetes especially diabetic ketoacidosis. Although the management of DKA has been markedly improved in recent years in association with the general healthcare improvements, it is still a public health problem. It is a life threatening medical emergency with a mortality rate $<5 \%$ in individuals under 40 years of age in a tertiary care hospital but with a more ominous prognosis in elderly who have mortality rate $>20 \%$. If the clinical features and biochemical abnormalities of DKA patients are recognized earlier and management given promptly then DKA related mortality rate will be less.

From the study it can be concluded that infection control and regular administration of insulin, good control of blood sugar and proper DSME (Diabetes Self Management Education) with appropriate sick days management can prevent diabetic ketoacidosis.

\section{References:}

1. Kitabchi AE, Umpierrez GE, Miles JM, Fisher JN. Hyperglycemic crises in adult patients with diabetes. Diabetes Care 2009; 32 (7): 1335-43.

2. Lin SF, Lin JD, Huang YY. Diabetic ketoacidosis: comparisons of patient characteristics, clinical presentations and outcomes today and 20 years ago. Chang Gunh Med J.2005 Jan; 28 (1): 24-30.

3. Zabeen B, Nahar J, Mohsin M, Azad K, Nahar N. Diabetic ketoacidosis in children-an experience in a tertiary hospital. Ibrahim Med. Coll. J. 2008; 2(1): 17-20.
4. Seyoum B, Herhanu P. Profile of diabetic ketoacidosis in a predominantly African American urban patient population. Ethnicity \& Disease. 2007; 17:234-237.

5. Rajasoorya C, Wong SF, Chew LS. Diabetic Acidosis- A study of 33 episodes. Singapure MED J 1993; 34: 381-438.

6. Wyckoff J, Abrahamson MJ. Diabetic Ketoacidosis and Hyperosmolar Hyperglycaemoc state. In: Kahn CR, Weir GC, King GL, Jacobson AM, Moses AC, Smith RJ editors. Joslin's Diabetes Mellitus. 4th ed. Bosston: Joslin's Diabetes Center.2005.p890-1.

7. Frier BM, Fisher M. Diabetes Mellitus. In: Boon NA, Colledge NR, Walker BR, Hunter JAA editors. Davidson's Principles \& Practice of Medicine. 21st ed. Edinburgh: Churchil Livingstone.2010.p 809-12

8. Hansen TK, Moller N. Acute Metabolic Complications of Diabetes: Diabetic Ketoacidosis and Hyperosmolar Hyperglycaemia. In: Holt R, Cockram CS, Flyvbjerg A, Goldstein BJ, editors. Textbook of Diabetes. 4th ed.UK:Willey-Blackwell; 2010.p.550-1

9. Ko SH, Lee WY, Lee JH, et al. Clinacal characteristics of diabetic ketoacidosis in Korea over the past two decades. Diabet Med. 2005 Apr; 22(4):466-9

10. Jahagirdar RR, Khadilkar VV, Khadilkar AV, Lalwani SK. Management of diabetic ketoacidosis in PICU. Indian $\mathrm{J}$ Pediatr.2007; 74 (6):551-4

11. Mbugua PK, Otieno CF, Kayima JK, Amayo AA, McLigeyo SO. Diabetic ketoacidosis: clinical presentation and precipitating factors at Kenyatta National Hospital, Nairobi. East Afr Med J. 2005; 82 (12): 191-6

12. Kiraly J, Becker CE, Williams HE. Diabetic ketoacidosis: A review of cases at a university Medical center. California Medicine: The Western Journal of Medicine. 1970; 3:3-9

13. Henriksen OM, Prahl JB, Roder ME, Svendsen OL. Treatment of diabetic ketoacidosis in adults in Denmark: a national survey. Diabetes Res Clin Pract. 2007; 77(1): 113-9. 